\title{
In Vitro Immunization: Perspectives on the Development of a System to Assess Vaccine Immunogenicity
}

\author{
Jorge Bravo-Madrigal* and Mario Alberto Flores-Valdez
}

Research andAssistance in Technologyand Designof Jalisco, AC Unit, Medical Biotechnology and Pharmaceutical, Mexico

Vaccines require exhaustive research for evaluating the level of protection it will provide against the target pathogen. In the development of a vaccine, usually three main steps are considered: nonclinical trials, which aims to evaluate the adequate physical and chemical proprieties as well as stability, sterility, adjuvants and the process of manufacturing [1]; preclinical trials, that are aimed at defining the safety and toxicity of the vaccine and also the potency and immunogenicity by using an appropriate animal model; and clinical trials, which are the final step and are carried out in humans. The objective of clinical trials is to evaluate vaccine effectiveness and safety in the human population. It is mandatory for the development of this stage to receive an authorization from a government commission or ethical committee about the protocol since human being will be take part in the research [2].

In many countries, the preclinical trial needs to be approved by an Institutional Animal Care Committee because every experiment using animals or a procedure must be justified and must be carried out according to animal protection laws. There are three main goals in the management of animals for research: reduce the number of lab animals; refining experiments with lab animals; and replacing the method or procedure that employs lab animals by alternatives, i.e. tissue culture assays. Some of the preclinical experiments are focused on assessing the protection against the pathogen induced by the vaccine. Up until now, this has been performed in animal models such as mice, rabbits, rats, ferrets or Guinea pigs. After immunization, the animal is used to evaluate a variety of cellular and/or humoral responses. However, research for developing a vaccine assessment system should be needed to replace or at least reduce the amount of animals for preclinical trials.

The in vitro production of monoclonal antibodies is an example of how policies were applied to replace lab animals in the development of new products. For the implementation of in vitro procedures it was necessary to adapt the growth of hybridomes by using in vitro cultures. Nowadays, it is possible to get these cultures in stationary as well as in suspension systems by using special chambers [3] or bioreactors [4,5]. These technologies do not use lab animals, therefore avoiding the traumatic procedure to get antibodies from ascites fluid $[6,7]$. Hybridomes are fusions of a specific antibody-producing $B$ cell with myeloma cell-lines, which is able to produce high amounts of immunoglobulin chains. When stimulated with interleukins such as IL2, or IFN- $\gamma$ a high production of monoclonal antibodies are created [8].

On the other hand, the advances in this field have led to the development of in vitro immunizations systems. Thakur et al. [9] isolated Peripheral Blood Mononuclear Cells (PBMC) from healthy donors and carried out a co-culture with activated dendritic cells, which, in turn, were able to present the antigen that was added to the medium. The final result was the proliferation and generation of plasma cells able to deliver antibodies against the added antigen. In this model an oligodeoxynucleotide, identified as $\mathrm{CpG}$, was also employed which is a signal of the maturation of B lymphocytes into plasmatic cells [10].

In light of these results, we consider that there is value in performing research and adaptation of the above systems in order to develop an in vitro immunization system, specifically designed to evaluate vaccine immunogenicity. The technology of the production of antibodies by in vitro methods, if were adapted to testing vaccines, could reduce the time needed to evaluate the immune response induced by any antigen. Additionally, the in vitro immunization approach would be faster because the cell interaction would be readily accesible. Once the production began, according to previous experiments, it is easy to quantify the amount of antibodies secreted to the medium as well as to analyze if the antibodies are able to inactivate or protect against the cellular infection from the target pathogen. Also, is it important to note that the antigen presentation process must be considered a fundamental stage, because the kind of fragments presented to the $\mathrm{B}$ cells will be the targets for the antibodies produced by the plasmatic cells.

Although replacing or reducing animals in the preclinical assessment would be desirable, the research with tissue cultures in this way must support that both models, in vitro or in vivo, show similar conclusions. It might well be required to validate every type of antigen before carrying out a definitive experiment.

If we could get valid data about the in vitro immunogenicity from any antigen, we could have elements to decide if the antigen or candidate vaccine has better probabilities to show an adequate protection in the animal model. In fact, we could reduce the number of animals for preclinical trials and refine the procedure so as to avoid using animals for testing antigens that showed a low or bad immunogenic response.

\section{References}

1. Organization WH (2003) Annex 1 Who Guidelines On Nonclinical Evaluation of Vaccines. World Health Organization, Geneve 1-27.

2. Organization WH (2004) Annex 1 Guidelines on clinical evaluation of vaccines: regulatory expectations. WHO Technical Report, Series No 924, 2004. World Health Organization, Geneva 35-101.

3. Trebak M, Chong JM, Herlyn D, Speicher DW (1999) Efficient laboratory-scale production of monoclonal antibodies using membrane-based high-density cell culture technology. J Immunol Methods 230: 59-70.

4. Dewar V, Voet P, Denamur F, Smal J (2005) Industrial implementation of in vitro production of monoclonal antibodies. ILAR J 46: 307-313.

5. Falkenberg FW, Weichert H, Krane M, Bartels I, Palme M, et al. (1995) In vitro production of monoclonal antibodies in high concentration in a new and easy to handle modular minifermenter. J Immunol Methods 179: 13-29.

6. Potter M (1972) Immunoglobulin-producing tumors and myeloma proteins of mice. Physiol Rev 52: 631-719.

*Corresponding author: Jorge Bravo-Madrigal, Research and Assistance in Technology and Design of Jalisco, AC Unit, Medical Biotechnology and Pharmaceutical, Mexico, Tel: 013333455200; Email: jbravo@ciatej.mx

Received February 14, 2014; Accepted February 17, 2014; Published February 19, 2014

Citation: Bravo-Madrigal J (2014) In Vitro Immunization: Perspectives on the Development of a System to Assess Vaccine Immunogenicity. J Bacteriol Parasitol 5 e121. doi:10.4172/2155-9597.1000e121

Copyright: $\odot 2014$ Bravo-Madrigal. This is an open-access article distributed under the terms of the Creative Commons Attribution License, which permits unrestricted use, distribution, and reproduction in any medium, provided the original author and source are credited. 
Citation: Bravo-Madrigal J (2014) In Vitro Immunization: Perspectives on the Development of a System to Assess Vaccine Immunogenicity. J Bacteriol Parasitol 5: e121. doi:10.4172/2155-9597.1000e121

Page 2 of 2

7. Hendriksen CF, de Leeuw W (1998) Production of monoclonal antibodies by the ascites method in laboratory animals. Res Immunol 149: 535-542.

8. Borrebaeck CA, Danielsson L, Möller SA (1988) Human monoclonal antibodies produced by primary in vitro immunization of peripheral blood lymphocytes. Proc Natl Acad Sci U S A 85: 3995-3999.
9. Thakur A, Norkina O, Lum LG (2011) In vitro synthesis of primary specific antibreast cancer antibodies by normal human peripheral blood mononuclear cells. Cancer Immunol Immunother 60: 1707-1720.

10. Jung J, Yi AK, Zhang X, Choe J, Li L, et al. (2002) Distinct response of human $B$ cell subpopulations in recognition of an innate immune signal, CpG DNA. J Immunol 169: 2368-2373. 